\title{
Protective Role of Parenting Attitude on the Behavioral and Neurocognitive Development of the Children from Economically Disadvantaged Families
}

\author{
Da-Eun Jung ${ }^{1,2}$, Soo-Young Bhang ${ }^{3}$, Won-Hye Lee ${ }^{4}$, \\ Hae-Joo Yoon ${ }^{4}$, Hee-Yeon Jung ${ }^{5,6} \bowtie$, and Yeni Kim ${ }^{2} \bowtie$ \\ ${ }^{1}$ Suwondongbu Branch Office, Gyeonggi-Incheon Regional Headquarter, National Health Insurance Service, Suwon, Republic of Korea \\ ${ }^{2}$ Department of Child and Adolescent Psychiatry, National Center for Mental Health, Seoul, Republic of Korea \\ ${ }^{3}$ Department of Psychiatry, Gangnam Eulji Hosipital, Eulji University, Seoul, Republic of Korea \\ ${ }^{4}$ Department of Clinical Psychology, Seoul National Hospital, Seoul, Republic of Korea \\ ${ }^{5}$ Department of Psychiatry and Behavioral Science and Institute of Human Behavioral Medicine, Seoul National University College of Medicine, \\ Seoul, Republic of Korea \\ ${ }^{6}$ Department of Neuropsychiatry, SMG-SNU Boramae Medical Center, Seoul, Republic of Korea
}

Objective Association between home environment and the behavioral and neurocognitive development of children from a community childcare center for low-income families was examined (aged 6 to 12 years, $n=155$ ).

Methods The parents performed a questionnaire on home environment (K-HOME-Q) to assess home environment including parenting attitude and the Child Behavior Checklist (K-CBCL). The children performed the Wechsler Intelligence (IQ) Scale, Stroop interference test (Stroop), word fluency test (WF), and design fluency test (DF) to assess their neurocognitive development.

Results 'Nurturing of Development' and 'Variety of Language Interaction' scores from the K-HOME-Q, were inversely associated with total behavior problems, externalization, rule-breaking, and aggressive behavior subscales of K-CBCL, and 'Emotional atmosphere' and 'Tolerance toward the child' scores showed inverse associations with the total behavior problems, rule-breaking, aggressive behavior, and withdrawn/depressed subscales. Despite economic hardship, the mean scores of the neurocognitive tests were comparable to the average level of Korean children's normative sample. However, 'Nurturing of Development' and 'Tolerance toward the Child' score of KHOME-Q were associated with better executive function (IQ, WF, DF).

Conclusion These results suggest that parental stimulation of development and tolerant parenting attitude may offer protection against the negative effects of suboptimal economic environment on children's behavior and neurocognitive development.

Psychiatry Investig 2018;15(6):584-592

Key Words Parenting, Home environment, Nurturing, Behavior, Neurocognitive, Development.

\section{INTRODUCTION}

It has been widely recognized that economic hardship has a negative impact on children's development. ${ }^{1,2}$ Children from

Received: May 31, 2017 Revised: September 25, 2017

Accepted: December 25, 2017

$\triangle$ Correspondence: Yeni Kim, MD, PhD

Department of Child and Adolescent Psychiatry, National Center for Mental Health, 127 Yongmasan-ro, Gwangjin-gu, Seoul 04933, Republic of Korea Tel: +82-2-2204-0138, Fax: +82-2-2204-0393, E-mail: yenikim@korea.kr

$\triangle$ Correspondence: Hee-Yeon Jung, MD, $\mathrm{PhD}$

Department of Neuropsychiatry, SMG-SNU Boramae Medical Center, 20 Boramae-ro 5-gil, Dongjak-gu, Seoul 07061, Republic of Korea

Tel: +82-2-870-2461, Fax: +82-2-870-3866, E-mail: hyjung@snu.ac.kr

(a) This is an Open Access article distributed under the terms of the Creative Commons Attribution Non-Commercial License (http://creativecommons.org/licenses/by$\mathrm{nc} / 4.0$ ) which permits unrestricted non-commercial use, distribution, and reproduction in any medium, provided the original work is properly cited. economically deprived families exhibit behavioral and emotional problems more often than children from families with adequate economic resources. ${ }^{3}$ Studies have also shown associations between low income and the behavior and emotional well-being of children as young as 3 to 5 years of age. ${ }^{4,5}$ Childhood socioeconomic circumstances are also associated with long-term effects in adulthood including physical and mental health. ${ }^{3,4,6}$ Part of the problems caused by the children in economically deprived environment is mediated by difficulties in parental emotional well-being and decreased parenting skills. ${ }^{6}$ Children are heavily dependent on their parents and home life as the foundation for later development. ${ }^{7}$ The quality of parenting practices and the overall home environment plays major roles in individuals' cognitive and non-cog- 
nitive development at the different developmental stages. ${ }^{1,8}$

There are several hypotheses regarding how parenting mediates the development of behavior and executive function in children. The child's temperament, ethnicity, and cultural differences modulate the effects of parenting behavior on a child's development. ${ }^{9}$ Biological mechanisms implicate the involvement of the hypothalamus-pituitary-adrenal axis. ${ }^{10}$ Executive functions are higher order processes, such as inhibitory control and cognitive flexibility, that enable individuals to display goal-directed actions and adaptive responses to situations. ${ }^{11}$ The brain circuits related to these higher executive functions develop in early to late childhood and may result in behavioral control abilities or difficulties.

Not all economically deprived homes share the same general attributes. The degree and nature of the risk of particular developmental problems vary from home to home. It is crucial to specifically identify the particular risk for a given developmental problem and to plan preventive or ameliorative strategies. ${ }^{12}$ Previous studies have shown that what parents and care-takers do with their young children makes a real difference to the children's development and is more important than the parent's socio-economic status or educational level. It has also been suggested that parental attitudes and behavior, particularly parents' involvement in home learning activities, can be critical to children's achievement and can overcome the influences of other family members and other aspects of the home environment. ${ }^{13}$

In this study, our aim was to explore the association between home environmental factors including parenting attitude and the behavioral problems and executive functions in economically disadvantaged children aged 6 to 12 years. These children came from economically deprived families whose physical environment may not reach the national average. We questioned parents on the home environment including their parenting attitude, and physical environment. Behavioral neurocognitive tests were administered to the children to assess their executive function abilities.

\section{METHODS}

\section{Participants}

The participants were recruited from a community child center. The community child center in Korea was established to provide after-school child welfare services to children who qualify for social security, near-poverty group, and those who got a recommendation of organization which had a public confidence among can prove a family income of lower than $70 \%$ of the national average.

A total of 155 participants from community child centers in Seoul and Ulsan were enrolled in this study. The study pro- tocol was approved by the Institutional Review Board of SMGSNU Boramae Medical Center (IRB No. 26-2014-41), and all study participants provided written informed consent at enrollment. The Children were administered the Korean Wechsler Intelligence Scale for Children-Third Edition (KWISC-III; $n=149)$, the Stroop interference test $(n=142)$, a word fluency test $(n=142)$ and a design fluency test $(n=152)$. Their mothers completed the Korean version of the Child Behavior Checklist (K-CBCL; n=149) and answered a Korean questionnaire of parenting attitude and home environment developed from Home Observation for Measurement of the Environment (K-HOME-Q, n=129) by Jang. ${ }^{14}$

\section{Measures}

\section{Parental Questionnaire of Home Observation for Measurement of the Environment (K-HOME-Q)}

Home Observation for Measurement of the Environment $(\mathrm{HOME})^{11}$ is an interview of parenting attitude and home environment performed by a rater. HOME is designed to measure the quality and extent of stimulation available to a child in the home environment. Both interaction with the parent and the physical environment are assessed by direct observation. ${ }^{11}$ In this study, we administered an 87-item parental questionnaire developed from HOME (K-HOME-Q) by Jang $^{14}$ (Cronbach's alpha $=0.859$ ); to measure diverse variables associated with parenting behaviors and home environment. The questionnaire was performed by the parents examined the following nine factors; 1) Living Environment Stability, 2) Nurturing of Development, 3) Variety of Language Stimulation, 4) Tolerance toward the Child, 5) Emotional Atmosphere, 6) Nurturing of Independence, 7) Variety of Experiences, 8) Physical Living Environment, and 9) Variety of Learning Materials.

\section{Assessment of behavior: Korean Child Behavior Checklist (K-CBCL)}

The Korean version of the Child Behavior Checklist ${ }^{15,16}$ was used to assess externalizing and internalizing behavioral problems. This checklist consists of 120 questions about the child's behavior. Parents rate how often their children exhibit each type of behavior on 3 -point scale $(0=$ not true, $1=$ somewhat or sometimes true, $2=$ very true or often true). The three categories of the Behavior problem scale (Total Behavior Problems Scale, Externalization Scale and Internalization Scale) and the nine Behavior problem syndrome subscales (RuleBreaking Behavior, Aggressive Behavior, Anxious/Depressed, Withdrawn/Depressed, Somatic Complaints, Social Problems, Thought Problems, Attention Problems, and Other Problems) were used for analysis. 


\section{Assessment of neuropsychological development}

The Korean Wechsler Intelligence Scale for Children-Third Edition, ${ }^{17,18}$ was used to assess general intelligence. Neuropsychological tests ${ }^{19}$ including the Stroop test, a word fluency test and a design fluency test were used to assess executive function.

\section{Stroop test}

The Stroop test is well known as a measure of selective attention and cognitive control. There are many versions of the Stroop test. This study used the Stroop test developed by Kim, ${ }^{19}$ which has been standardized for children and adolescents in South Korea. It consists of three trials. In the first trial, called the "simple task," the subject must say the names of the colors of dots printed in colored ink (e.g., blue, red, yellow, black). In the second trial, called the "middle task", the subject must read words (e.g., when, what, come, go) printed in colored ink. In the final trial, called the "interference task," the subject must say the word's color instead of the word itself, which is the name of a color other than the one in which it is printed. This test is scored according to response time. The standard score for the interference task was used in our analysis.

\section{Word fluency test}

The word fluency test was developed to assess executive functions such as conceptual mental flexibility, switch response sets and self-monitoring. ${ }^{20,21}$ This study used a phonemic word fluency test that was standardized for Korean children and adolescents by Kim. ${ }^{19}$ The subject was asked to say as many words as possible beginning with a given letter of the Korean alphabet within 60 seconds. Three letters (two consonants and one vowel) were used for this test. This test was scored according to the total number of correct responses. The standard score of the test was used in our analysis.

\section{Design fluency test}

The design fluency test was developed to assess nonverbal mental flexibility as a counterpart of the word fluency test. ${ }^{21}$ This study used the design fluency test developed by Kim, ${ }^{19}$ which has been standardized for children and adolescents in South Korea. This test consists of three parts. Each part includes 35 matrices $(5 \times 7)$, with five dot-arrangements. The five dot arrangements were slightly different in each part. For each part, the subject was asked to draw as many different figures as possible within 60 seconds by connecting any number of five dots using straight lines. This test was scored by the total number of correct responses. The standard score of the test was used in our analysis.

\section{Statistical analysis}

All statistical analyses were performed using SPSS 19.0 for Windows (IBM Corp., Armonk, NY, USA). The characteristics of the study subjects with respect to Questionnaire of the home environment where the children are living scores were analyzed using $\chi^{2}$ tests for categorical variables and t-tests for continuous variables. The following key covariates were used in this study: paternal education, family income and residential area. Generalized linear relationships (GLM) were modeled using the K-CBCL standard score, the K-WISC-III full-scale intelligence quotient, the Stroop interference test standard score and the word/design fluency test raw and standard scores as the outcome variables and the Questionnaire of the home environment scores as the predictor variables. Both the K-CBCL standard scores and the Questionnaire of the home environment scores were used as continuous variables.

\section{RESULTS}

\section{Participant characteristics}

The gender and geographical distribution of the 155 subjects included in the analysis was as follows: male $(n=78$, $50.3 \%)$, female ( $n=77,49.7 \%)$, Seoul ( $n=94,60.6 \%)$; and Ulsan $(n=61,39.4 \%)$. The participants' demographic data are provided in Table 1 . The mean \pm standard deviation of the Stroop interference test standard score, the word fluency standard score and the design fluency standard score were $9.89 \pm 3.32,9.23 \pm 3.09$, and 9.31 \pm 3.37 , respectively. There were no statistically significant differences between the 149 families included in the analysis and the 6 families who were excluded from the analysis of the children's behavioral and neuropsychological developmental evaluation because of a lack of one of the survey items. There were significant differences between those who were included and those who were excluded from the study with respect to residential area $\left(\chi^{2}=\right.$ 4.570, $\mathrm{df}=1, \mathrm{p}<0.046)$, family income $\left(\chi^{2}=94.357, \mathrm{df}=4, \mathrm{p}<\right.$ $0.001)$, and paternal education $\left(\chi^{2}=50.188, \mathrm{df}=3, \mathrm{p}<0.001\right)$, but there were no significant differences in the gender of their children.

\section{The Home Environment (K-HOME-Q) items endorsement frequency}

The items most often endorsed by the Korean care takers about the home environment using K-HOME-Q, were 'Reasons explained before punishment (95.3\%)' and 'Child chooses his/her own clothes (92.2\%).' A total of $91.5 \%$ of the mothers reported that they 'Introduce the child to visiting guests' and $87.6 \%$ of the mothers said they 'Check on the child when the child is in another room' (Table 2). A total of $68.8 \%$ of the parents reported that they 'Display the child's drawings 
Table 1. Demographic characteristics of the children $(\mathrm{N}=155)$

\begin{tabular}{|c|c|c|c|}
\hline Demographics & $\mathrm{N}(\%)$ & Neurocognitive assessment & Mean \pm SD \\
\hline Sex & & K-CBCL standard score $(\mathrm{N}=122)$ & \\
\hline Male & $78(50.3)$ & Total behavior problems & $52.23 \pm 10.03$ \\
\hline Female & $77(49.7)$ & Externalization & $52.61 \pm 9.19$ \\
\hline Income per year & & Rule-breaking behavior & $54.39 \pm 5.45$ \\
\hline$>\$ 2,000$ & $15(9.6)$ & Aggressive behavior & $55.35 \pm 6.52$ \\
\hline$\$ 1,200-\$ 2,000$ & $63(40.6)$ & Internalization & $51.00 \pm 10.15$ \\
\hline$<\$ 1,200$ & $55(35.5)$ & Anxious/depressed & $54.04 \pm 5.80$ \\
\hline Unknown & $22(14.2)$ & Withdrawn/depressed & $54.46 \pm 6.68$ \\
\hline Residential area & & Somatic complaint & $54.40 \pm 6.75$ \\
\hline Seoul & $94(60.6)$ & Social problems & $56.16 \pm 6.98$ \\
\hline Ulsan & $61(39.4)$ & K-WISC-III $(\mathrm{N}=149)$ & \\
\hline Paternal education & & FSIQ & $96.96 \pm 18.50$ \\
\hline$\leq$ Middle school & $15(9.7)$ & Stroop test $(\mathrm{N}=142)$ & \\
\hline$\leq$ High school & $76(49.0)$ & Interference test standard score & $9.89 \pm 3.32$ \\
\hline$\geq$ University & $26(16.8)$ & Fluency test $(\mathrm{N}=142)$ & \\
\hline \multirow[t]{2}{*}{ Unknown } & $38(24.5)$ & Word fluency standard score & $9.23 \pm 3.09$ \\
\hline & & Design fluency standard score & $9.31 \pm 3.37$ \\
\hline
\end{tabular}

K-CBCL: Korea-Child Behavior Checklist, K-WISC-III: Korea-Wechsler Intelligence Scale for Children-III, FSIQ: Full Scale Intelligence Quotient

and art work at home' and that there are 'Safe play environments outside the home.' Only $54.3 \%$ of the parents reported that the 'Child has his/her own room.'

\section{The Home Environment (K-HOME-Q) and Korean Child Behavior Checklist (K-CBCL)}

In GLM analysis, 'Nurturing of Development' was inversely associated with the total behavior problems standard score $(\beta=-1.763, p=0.001)$, the externalization standard score $(\beta=-1.729, p=0.001)$, rule-breaking behavior $(\beta=-0.617$, $\mathrm{p}=0.049)$, aggressive behavior $(\beta=-0.984, \mathrm{p}=0.006)$ and social problems $(\beta=-0.869, \mathrm{p}=0.026)$ after adjusting for paternal education, family income, and residential area. 'Variety of Language Interactions' was inversely associated with the total behavior problems standard score $(\beta=-1.128, p=0.027)$, the externalization standard score $(\beta=-1.298, \mathrm{p}=0.005)$, rulebreaking behavior $(\beta=-0.896, p=0.001)$ and aggressive behavior $(\beta=-0.861, \mathrm{p}=0.007)$ (Table 3).

'Tolerance toward the Child' was inversely associated with the total behavior problems standard score $(\beta=-1.440, \mathrm{p}=$ $0.033)$, the externalization standard score $(\beta=-1.468, p=0.018)$, rule-breaking behavior $(\beta=-0.885, p=0.022)$, aggressive behavior $(\beta=-0.974, p=0.024)$ and withdrawn/depressed $(\beta=$ -1.363, $\mathrm{p}=0.002)$. 'Emotional Atmosphere' showed an inverse association with the total behavior problems standard score $(\beta=-0.694, p=0.045)$, rule-breaking behavior $(\beta=-0.389$, $\mathrm{p}=0.045)$, aggressive behavior $(\beta=-0.590, \mathrm{p}=0.008)$, with- drawn/depressed $(\beta=-0.647, p=0.005)$ (Table 4$)$ and thought problems ( $\beta=-0.500, p=0.017$ ). 'Nurturing of Independence' showed an inverse association with the total behavior problems standard score $(\beta=-1.615, p=0.018)$, the externalizing problems standard score $(\beta=-1.467, \mathrm{p}=0.020)$, withdrawn/ depressed $(\beta=-0.948, p=0.039)$, thought problems $(\beta=-1.008$, $\mathrm{p}=0.014)$ and other problems $(\beta=-0.999, \mathrm{p}=0.042)$. 'Variety of Learning Materials' was inversely associated with social problems ( $\beta=-0.805, p=0.039$ ). 'Variety of experience and Physical living environment' showed no association with the $\mathrm{K}$-CBCL standard score subscales.

\section{The Home Environment (K-HOME-Q) and Neuropsychological Development}

In the GLM analysis, 'Living Environment Stability' was associated with the word fluency test standard score $(\beta=0.528$, $\mathrm{p}=0.027$ ), and 'Nurturing of Development' was associated with the K-WISC-III FSIQ score $(\beta=2.138, p=0.029)$, the raw score $(\beta=1.005, p=0.008)$ and standard score $(\beta=0.429, p=$ $0.014)$ of the word fluency test, the standard score $(\beta=0.388$, $\mathrm{p}=0.048)$ of the design fluency test and the standard score $(\beta=$ $0.437, p=0.023$ ) (Table 5) of the Stroop interference test. 'Tolerance toward the Child' showed a positive association with the K-WISC-III FSIQ score $(\beta=2.690, p=0.022)$, the raw score $(\beta=1.387, p=0.004)$ and standard score $(\beta=0.477, p=0.027)$ of the word fluency test and the raw score $(\beta=1.653, p=0.049)$ and the standard score $(\beta=0.533, p=0.027)$ of the design flu- 
Table 2 .The Home Environment (K-HOME-Q) items endorsement frequency ( $\mathrm{N}=129)$

\begin{tabular}{|c|c|c|}
\hline Item description & Endorsed & $\%$ \\
\hline \multicolumn{3}{|l|}{ Living environment stability } \\
\hline Child has regular time schedules & 107 & 82.9 \\
\hline Child has meals with family at least once a day & 88 & 68.2 \\
\hline Child spends $1-2$ hours or more with father ( $>4$ times week) & 60 & 46.5 \\
\hline Child has moved more than twice during the past year & 11 & 8.5 \\
\hline \multicolumn{3}{|l|}{ Nurturing of development } \\
\hline Parent recommend educational TV programs & 90 & 69.8 \\
\hline Child is encouraged to learn to tell time & 89 & 69.0 \\
\hline Child is encouraged to learn multiplication and division & 87 & 67.4 \\
\hline Child encouraged to learn skating or swimming & 60 & 46.9 \\
\hline \multicolumn{3}{|l|}{ Variety of language interaction } \\
\hline Child has conversations with family during meals & 106 & 82.2 \\
\hline Parent uses warm tone of voice with the child & 101 & 80.2 \\
\hline Parent has a pet name/endearment for the child & 87 & 67.4 \\
\hline Child has conversations with parents every day & 86 & 67.2 \\
\hline \multicolumn{3}{|l|}{ Tolerance towards the child } \\
\hline Child is allowed to keep his/her own things & 111 & 86.0 \\
\hline Child is given help when frustrated during a task & 107 & 82.9 \\
\hline Child is allowed to play with water or dirt & 103 & 79.8 \\
\hline Child is reprimanded when he/she spills food or water & 61 & 47.3 \\
\hline \multicolumn{3}{|l|}{ Nurturing of independence } \\
\hline Parent usually introduces the child to visiting guests & 118 & 91.5 \\
\hline Parent checks on the child when the child is in another room & 113 & 87.6 \\
\hline Parent hugs the child once or twice everyday & 102 & 79.1 \\
\hline Mother praises the child's behavior frequently & 95 & 73.6 \\
\hline \multicolumn{3}{|l|}{ Emotional atmosphere } \\
\hline Parent explains the reason before punishment & 123 & 95.3 \\
\hline Child is allowed to choose what to wear & 119 & 92.2 \\
\hline Child is allowed to make his/her choices when shopping & 115 & 89.8 \\
\hline Child is expected to follow certain sets of rules & 108 & 83.7 \\
\hline \multicolumn{3}{|l|}{ Variety of experience } \\
\hline Child is taken to out to eat 2-3 times a week & 91 & 70.5 \\
\hline Child goes to grocery shopping with the parents more than once a week & 84 & 66.1 \\
\hline Parent has taken the child to the movies or the theater in the past year & 72 & 55.8 \\
\hline Parent has taken the child to a museum or exhibitions in the past year & 54 & 41.9 \\
\hline \multicolumn{3}{|l|}{ Physical living environment } \\
\hline Child's room is relatively clean & 96 & 74.4 \\
\hline Child's drawings and art work are displayed at home & 88 & 68.8 \\
\hline Safe play environment outside the home & 88 & 68.8 \\
\hline Child has his/her own room & 70 & 54.3 \\
\hline \multicolumn{3}{|l|}{ Variety of learning materials } \\
\hline Child has at least 20 children's books (other than textbooks) & 112 & 86.8 \\
\hline Child has riding toys (bicycle, roller skates etc.) & 95 & 73.6 \\
\hline Child has a real musical instrument & 88 & 68.2 \\
\hline Child has blocks or similar building toys & 78 & 60.5 \\
\hline
\end{tabular}


DE Jung et al.
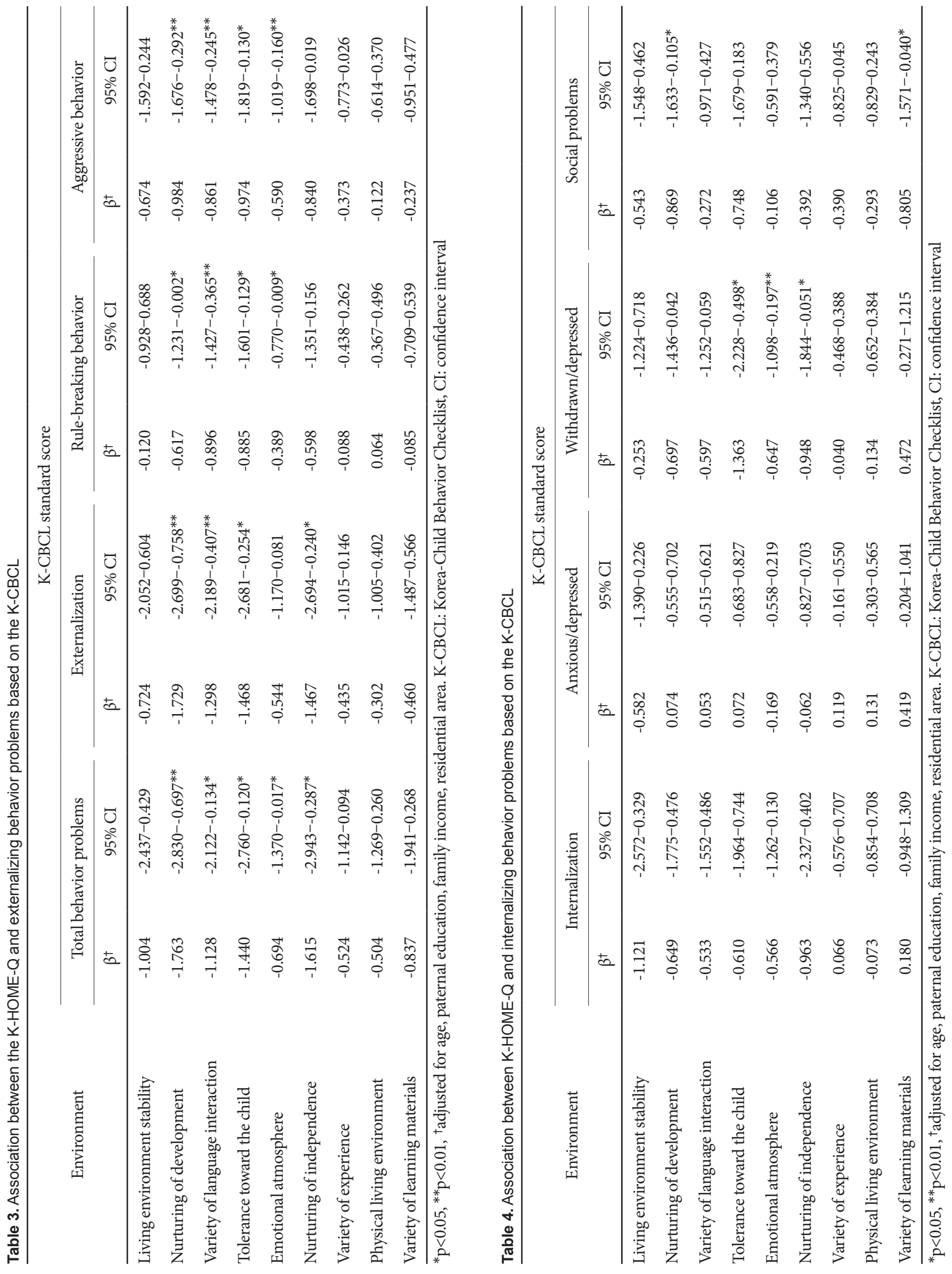


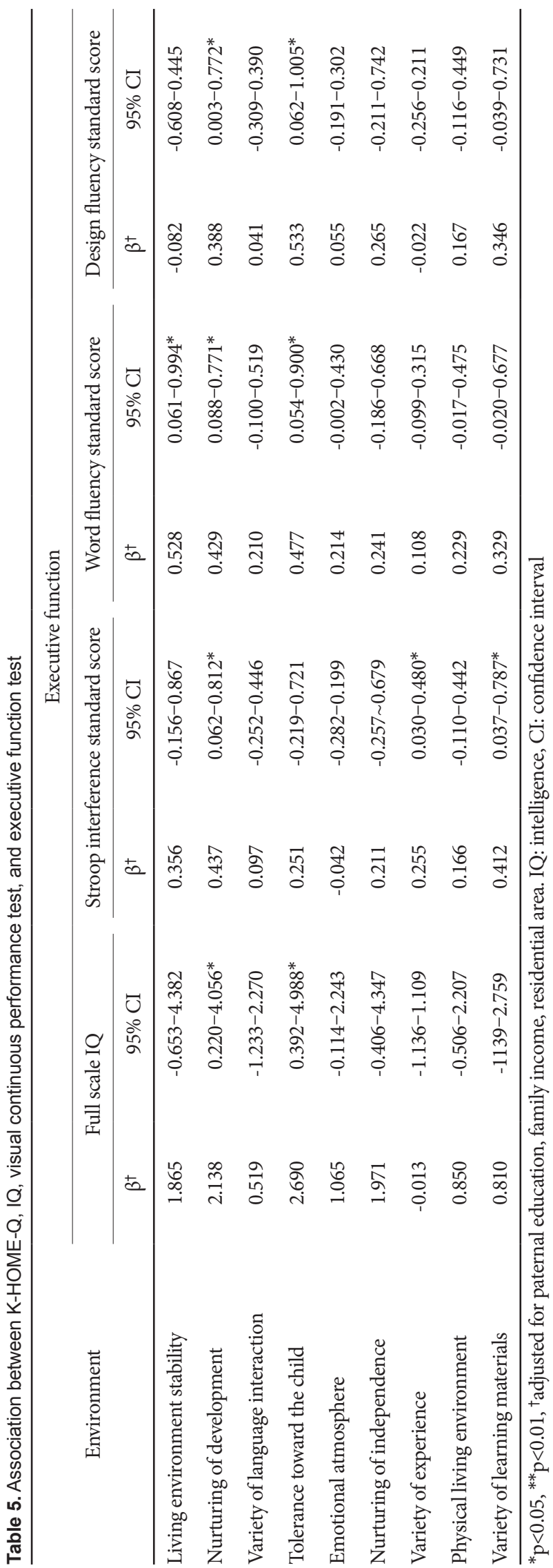

ency test. 'Variety of Experiences' was associated with the standard score $(\beta=0.255, p=0.027)$ of the Stroop interference test. 'Physical Living Environment' was associated with the raw score ( $\beta=0.688, p=0.018)$ of the word fluency test and 'Variety of Learning Materials' was associated with the standard score ( $\beta=0.412, p=0.031)$ of the Stroop interference test.

\section{DISCUSSION}

In this study, we explored the association between home environment including parenting attitude, and the behavioral and neurocognitive development of children from economically disadvantaged families. The participants in this study were recruited from community child centers, which provide after-school child welfare services to children from families who qualify for social security or can prove similar economic disadvantage. The items endorsed by the caretakers reflected some of these economic difficulties. For example, only about half of the parents reported that there were 'Safe play environments outside the home (68.8\%),' 'The child has his/her own room (54.3\%)', and that 'They had taken their children to a movie or the theater during the past year (55.8\%).' However, the items most often endorsed were 'Reasons were explained before punishment (95.3\%)' and 'The child chooses his/her own clothes (92.2\%)'. Majority of the families reported that' the child had conversations with the family during meal time (82\%)', 'children were introduced to visiting guests (91.5\%)' and that 'children were checked on when the children were in another room (87.6\%)'. The endorsement of these and other items show that most of the parents tried to nurture their children's independence and also tried to create a supportive emotional atmosphere despite economic hardships.

In this study, we found that the 'Nurturing of Development' and 'Variety of Language Interaction' scores were inversely associated with the total behavior, externalization, rule-breaking, and aggressive behavior subscales of the KCBCL. 'Emotional Atmosphere' showed an inverse association with the total behavior problems, rule-breaking, aggressive behavior, withdrawn/depressed and thought problems subscales of the K-CBCL. 'Tolerance toward the Child' was also inversely associated with the total behavior problems, externalization, rule-breaking, aggressive behavior subscales of the K-CBCL. Interestingly, 'Variety of Experiences,' 'Variety of Learning Materials' and 'Physical Living Environment' showed no association with the K-CBCL externalization or the internalization subscales.

Positive parental interactions have been reported to foster sustained growth in inhibitory control and cognitive flexibility, ${ }^{22}$ which all contribute to mitigating externalizing and 
aggressive behavior. Sensitive care-taking was reported to promote the internalization of regulatory functions in a child, ${ }^{23}$ which may be important in the suppression of externalization and rule-breaking behaviors. Another study reported that lack of parental warmth and parental hostility were the most predictive of behavioral problems. ${ }^{7}$ These findings are in line with previous findings that expressions of anger and annoyance, physical punishment and intrusiveness have the most significant impact on a child's externalizing behaviors. ${ }^{24-26} \mathrm{~A}$ more supportive presence, higher positive regard, and lower hostility from the parents were also associated with less externalization and aggressive behavior in their children. ${ }^{24-26}$ Furthermore, a study on adopted children showed that the home environment was associated with hyperactive/impulsive symptoms in both children with attention-deficit hyperactivity (ADHD) and their non-ADHD siblings. ${ }^{27}$

It is difficult to determine the precise relationship between socio-economic status and mental health problems, including behavioral problems in children. Substantial reports indicate that children from low-income families more often manifest symptoms of psychiatric disturbances, maladaptive social functioning and poor cognitive performances compared with children from more affluent circumstances. ${ }^{9}$ The interactive influences of various genetic and epigenetic susceptibilities modulate the environmental influences of parenting attitude and behavior, and future studies that investigate these interactions among various factors in relation to the development of a model of the emergence of developmental psychopathology are warranted.

The results of this study also show that mean scores of the FSIQ and most of neurocognitive tests given to the subjects were comparable to the average level of a Korean normative sample, ${ }^{18}$ despite the economic circumstances. However, we observed that parental 'Nurturing of Development' and 'Tolerance toward the Child' were associated with higher IQ scores and better executive function as measured by the standard scores of the Stroop interference task, the word fluency test and the design fluency test. This result suggests that economic disability by itself has less effect on the cognitive development children compared to positive parental interactions. The executive function and social development of children are strongly linked to factors in the home environment, ${ }^{28,29}$ especially Parental Warmth, Learning Stimulation, Access to Reading, and Outings/Activities subscales measured by the HOME, had significant associations with children's cognitive outcomes. ${ }^{7}$ Reports have also shown that parental stimulation of a child's learning mitigated the effects of prenatal smoking exposure on the child's executive function development, ${ }^{30}$ suggesting indirect mediating effect of parenting on children's cognitive development.
The results of this study show that parental sensitivity and stimulation, rather than physical environment e.g. learning materials, are associated with behavioral and neurocognitive development, suggesting that parental stimulation of development and tolerant parenting attitude, may offer protection against the negative effects of suboptimal economic environment on children's behavioral and neurocognitive development.

\section{Acknowledgments}

This study was supported by a grant from the National Center for Mental Health Research \& Education, the Seoul National Hospital, Republic of Korea.

\section{REFERENCES}

1. Bradley RH, Caldwell BM, Corwyn RF. The Child Care HOME Inventories: assessing the quality of family child care homes. Early Child Res Q 2003;18:294-309.

2. Brooks-Gunn J, Duncan GJ. The effects of poverty on children. Future Child 1997;7:55-71.

3. Bradley RH, Corwyn RF. Socioeconomic status and child development. Annu Rev Psychol 2002;53:371-399.

4. Kiernan KE, Huerta MC. Economic deprivation, maternal depression, parenting and children's cognitive and emotional development in early childhood1. Br J Sociol 2008;59:783-806.

5. Linver MR, Brooks-Gunn J, Kohen DE. Family processes as pathways from income to young children's development. Dev Psychol 2002;38: 719-734.

6. Martin MJ, Conger RD, Schofield TJ, Dogan SJ, Widaman KF, Donnellan $\mathrm{MB}$, et al. Evaluation of the interactionist model of socioeconomic status and problem behavior: a developmental cascade across generations. Dev Psychopathol 2010;22:695-713.

7. Han WJ, Leventhal T, Linver MR. The Home Observation for Measurement of the Environment (HOME) in middle childhood: a study of three large-scale data sets. Parenting 2004;4:189-210.

8. Eunice Kennedy Shriver National Institute of Child Health and Human Development. The NICHD Study of Early Child Care and Youth Development (SECCYD): Findings for Children Up to Age $41 / 2$ Years (054318). Washington, DC: U.S. Government Printing Office; 2006.

9. Duncan GJ, Brook-Gunn J. Family poverty, welfare reform, and child development. Child Dev 2000;71:188-196.

10. Fay-Stammbach T, Hawes DJ, Meredith P. Parenting influences on executive function in early childhood: a review. Child Dev Perspect 2014; 8:258-264.

11. Hughes C, Graham A, Grayson A. Executive Functions in Childhood: Development and Disorder. In: Oates J, Grayson A, Editors. Cognitive and Language Development in Children. Oxford, England: Blackwell, 2004, p.207-228.

12. Bradley RH, Caldwell BM, Rock SL, Hamrick HM, Harris P. Home observation for measurement of the environment: development of a home inventory for use with families having children 6 to 10 years old. Contemp Educ Psychol 1988;13:58-71.

13. Cole J. A Research Review: The Importance of Families and the Home Environment. London: National Literacy Trust; 2011.

14. Jang YA. A validation study on the home observation for measurement for the environment in elementary school children. J Korean Home Econ Assoc 1984;22:173-182.

15. Achenbach TM. Child Behavior Checklist/4-18. Burlington: University of Vermont; 1991.

16. Oh KJ, Lee H, Hong KE, Ha EH. Manual for the Korean Child Behavior Checklist. Seoul: Choongangchucksung Research Center; 1997.

17. Wechsler D. Wechsler Intelligence Scale for Children. San Antonio, TX: Psychological Corporation; 1949. 
18. Kwak GJ, Park HY, Kim CT. Korean-Wechsler Intelligence Scale for Children. Seoul: Special Education Publishing Co; 2001.

19. Kim HG. Manual for Kims Frontal Executive Function Neuropsychological Test for Childhood. Daegu: Neuropsychology; 2005.

20. Lezak MD. Neuropsychological Assessment, 4th Edition. New York: Oxford University Press; 2004.

21. Lezak M, Howieson D, Bigler E. Tranel D. Neuropsychological Assessment, 5th Edition. New York: Oxford University Press; 2012.

22. Clark CA, Sheffield TD, Chevalier N, Nelson JM, Wiebe SA, Espy KA. Charting early trajectories of executive control with the shape school. Dev Psychol 2013;49:1481-1493.

23. Bernier A, Carlson SM, Deschênes M, Matte-Gagné C. Social factors in the development of early executive functioning: a closer look at the caregiving environment. Dev Sci 2012;15:12-24.

24. Bradley RH, Corwyn R. From parent to child to parent...: Paths in and out of problem behavior. J Abnorm Child Psychol 2013;41:515-529.

25. Hipwell A, Keenan K, Kasza K, Loeber R, Stouthamer-Loeber M, Bean T. Reciprocal influences between girls' conduct problems and depres- sion, and parental punishment and warmth: a six year prospective analysis. J Abnorm Child Psychol 2008;36:663-677.

26. Pardini DA, Fite PJ, Burke JD. Bidirectional associations between parenting practices and conduct problems in boys from childhood to adolescence: the moderating effect of age and African-American ethnicity. J Abnorm Child Psychol 2008;36:647-662.

27. Mulligan A, Anney R, Butler L, O’Regan M, Richardson T, Tulewicz EM, et al. Home environment: association with hyperactivity/impulsivity in children with ADHD and their non-ADHD siblings. Child Care Health Dev 2013;39:202-212.

28. Burston A, Puckering C, Kearney E. At HOME in Scotland: validation of the home observation for measurement of the environment inventory. Child Care Health Dev 2005;31:533-538.

29. Totsika V, Sylva K. The home observation for measurement of the environment revisited. Child Adolesc Ment Health 2004;9:25-35.

30. Mezzacappa E, Buckner JC, Earls F. Prenatal cigarette exposure and infant learning stimulation as predictors of cognitive control in childhood. Dev Sci 2011;14:881-891. 